\title{
科学与生厏
}

\section{A.H. 湼斯来揚諾夫院士}

(苏联科学院院長)

現在末必还有这样的科学工作者, 他們至今还怀疑科学是由实踐所童生, 怀疑科学 在歷这中的出琴是为了回答生活的实际需要，怀疑科学的發展方淌也正是由这些需要所 决是的。同时也篦可怀疑，現代高度發展的科学的唯一社会职责是在于滿足社会的实际 需要, 特別是生这的需要。

当然，科学的特有的和基本的作用是認識作用。但是，对世界、自然界的深刻的科 学認識同样是追求这样一个社会目的, 就是能动地掌握自然界和社会的發展規徘, 利 用它來为社会和社会生度服务。这就是說，高大多枝的科学之樹是生根于实踐之中的。 而科学的成果忠丰富了实踐。尽可能多地得出成果——这是对科学的很自然的要求。

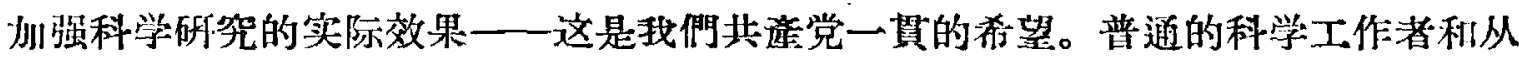

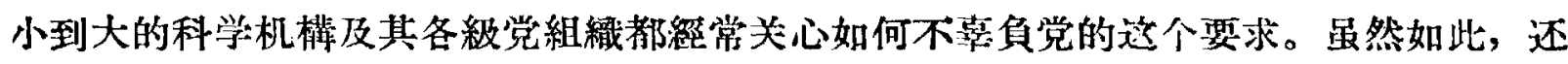
不能說情况是足以命人滿意的。苏共中央七月全会及在此以前石开的科学与工䅈工作者

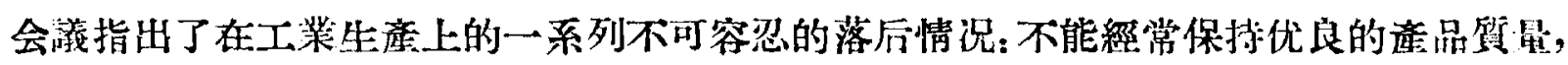
工.業中掌握新技術的迟䌊狀态，科学对技術的帮助不的等。

关于科学与工業相互配合方面的缺点，苏共中央七月全会指出，在許多工業部門中 将科学与技術的最重要的成就推廣于生逢的工作進行得很迟緵, 原有的工業后备力量也

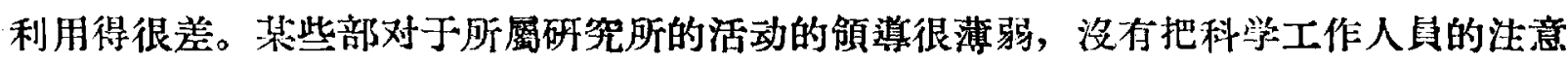
力集吓起來去解决技術發展中的主要任务, 已完成的科学工作的成果在牛推䗪的情 况也不能令人滿意。苏联科学院各科学研究机構和各部所屬呼究所各自为政地進行工. 作, 以致研筑題目常有重复。高等学校的大量科学干部很少被吸引到研究新技術間題的 工作中來。

共逢党和苏联政府已敉制定了一个巨大而具体的、以大規模地發㜆科学研究和計划

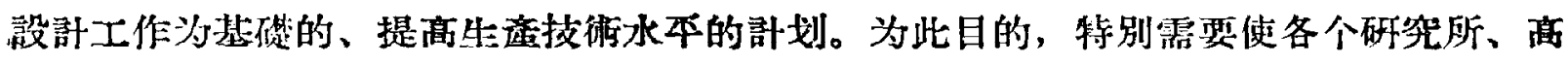

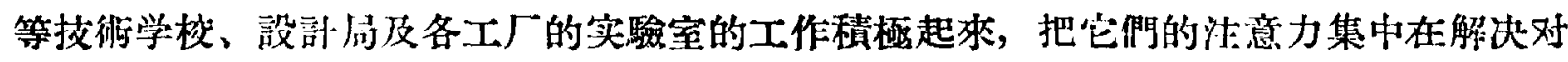

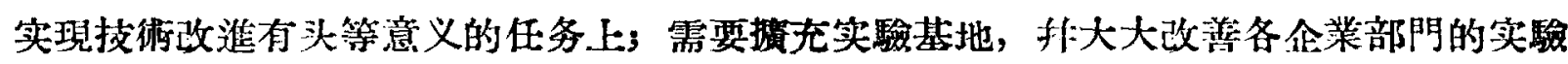
室、各科学研究机構和各高等学校的技術裝备。

苏共第二十炏代表大会关于第六个五年計划的指示真案，响苏联科学提出了一系列 極其重要和巨大的任务。我認为, 除了尽量加强科学的物澌基礎以外，在科学及其与生 的相互关系方面規定必要的組瀻制度，对于科学的發屡和解决这些巨大任务，都具有

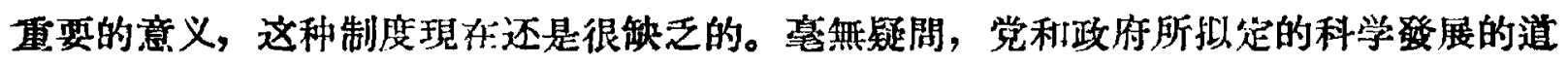




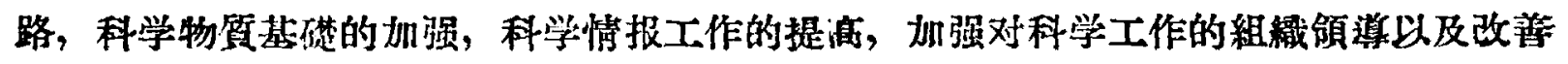
科学与生迹的协作等方案, 都能得到应有的效果。

科学研究的度大战綫在我國是在偉大十月社会主义茧命之后才建立的。在沙点俄國，

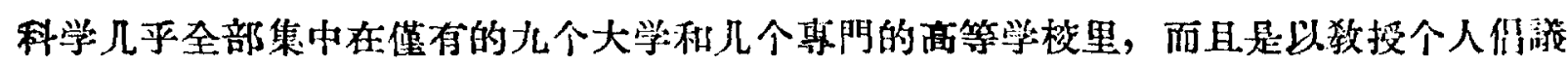

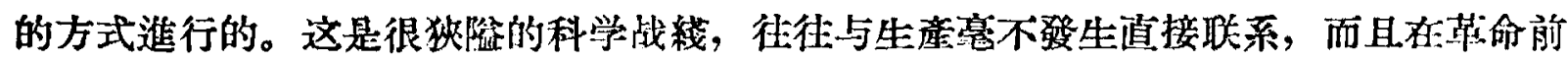

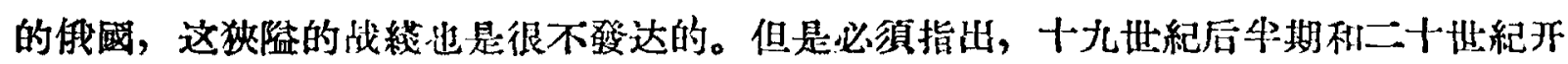
头的雨个十年中, 許多科学上头等重要的發現是在我國完成的。在物理与化学方爿一

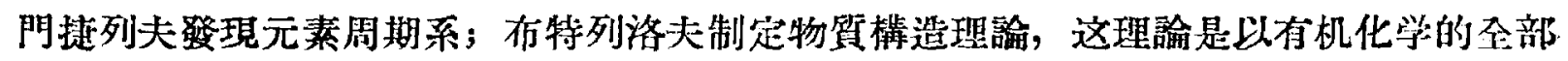

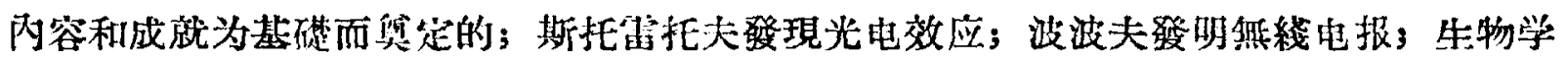

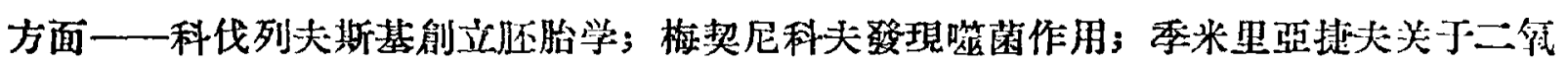

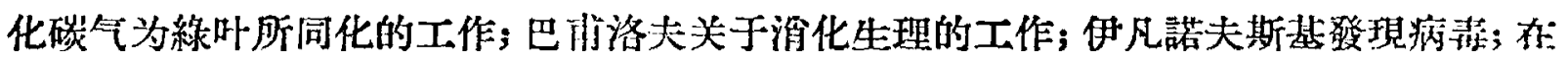

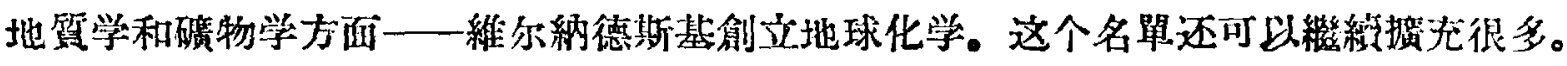

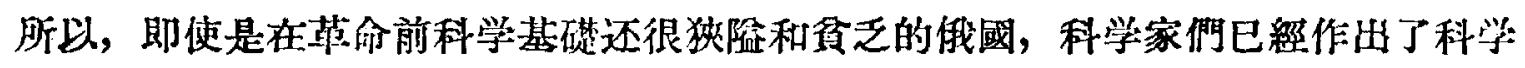
成就的光辉榜样, 其中最帒出的是門唗列夫的周期系, 这周期系是整个現代自然科学的

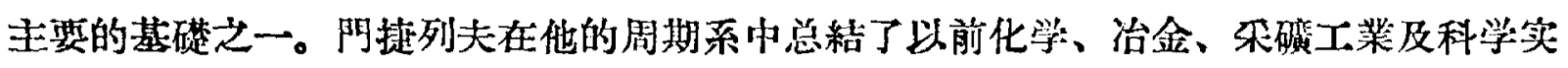
踐中得到的关于元素的全部知識。元素㕆期系生根于許多址紀的实路，而它的后果是与 以后的时代一一包括遥远的将來一一相联系的。光其是, 原子能的利用、牛導体拔獄、

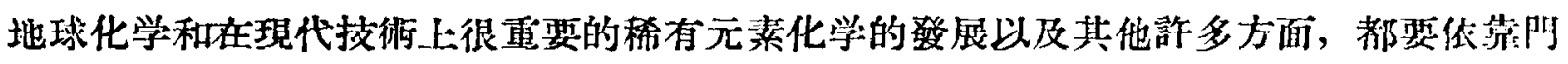

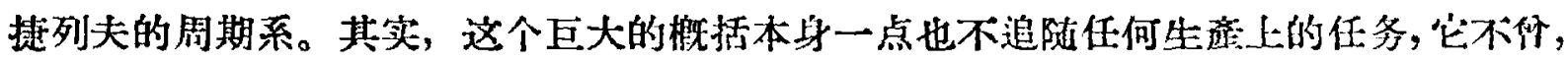

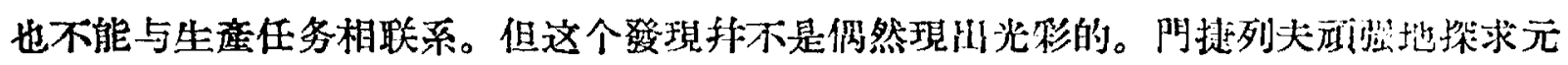
素的同族关系和它們有規律的排列次序。同时，他也有实际的目的，那就是问自己的学

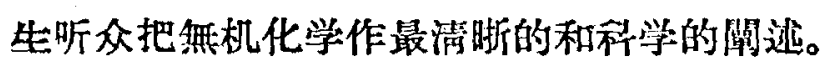

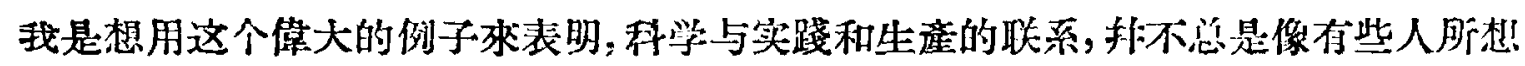

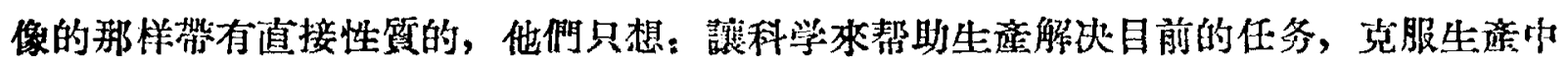

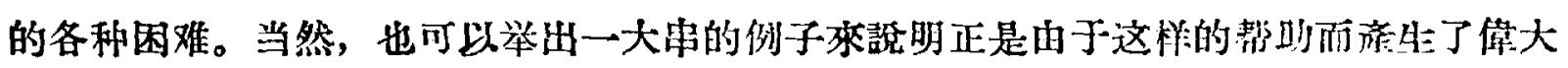

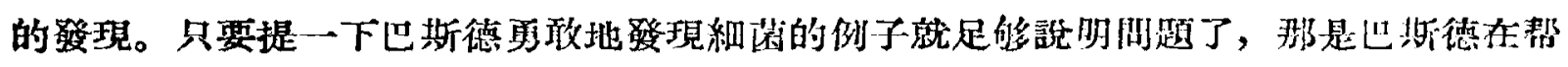

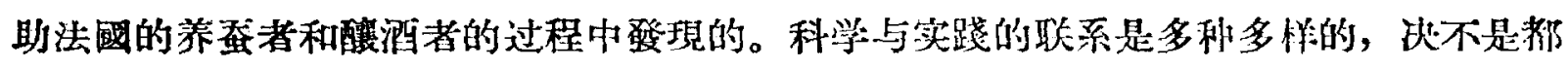

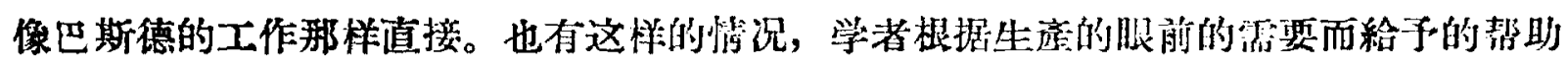

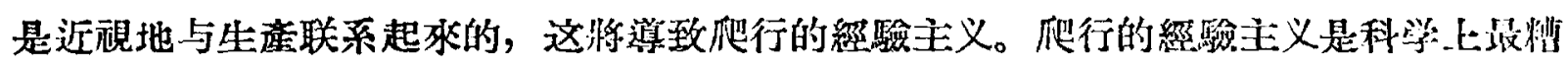
糕的道路。可以而且应該向科学提出的最大和最实际的要求, 硫是發現新的自然現像利 各現像間新的相互联系以及新的理諭的概括，以便利用这些得到的成就棅近速地在:约产: 上实現全新的、可使生产起草命变化的可能性。

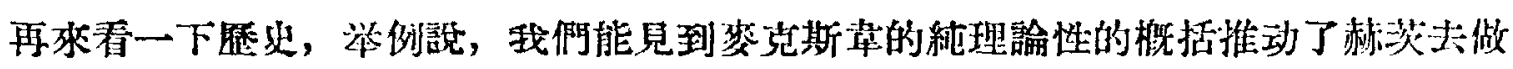

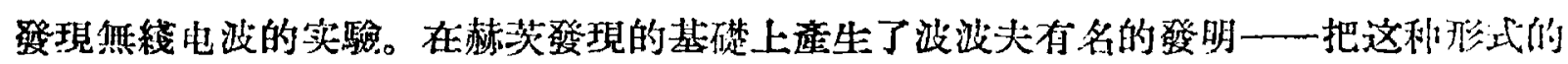

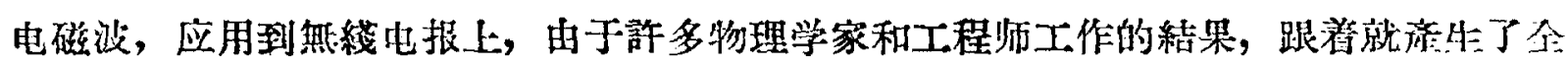

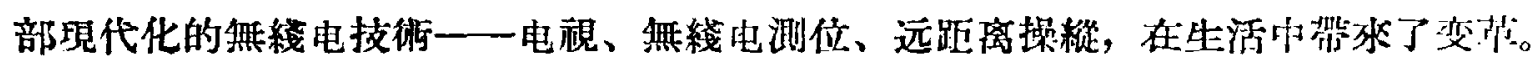

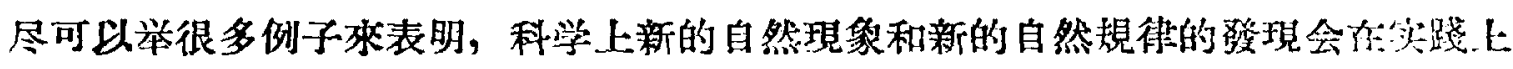

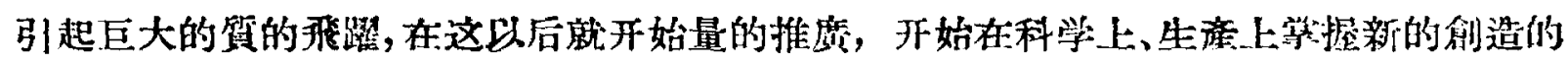


可丁能性。

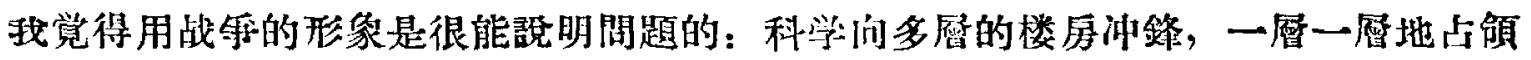

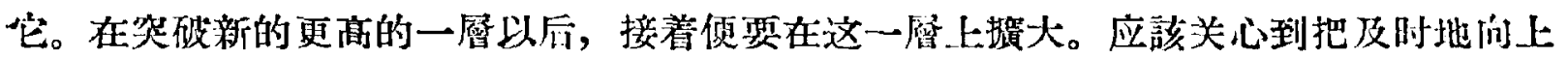

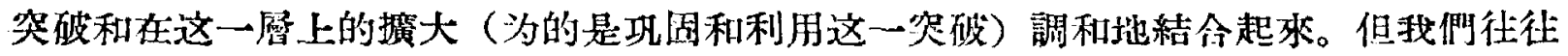

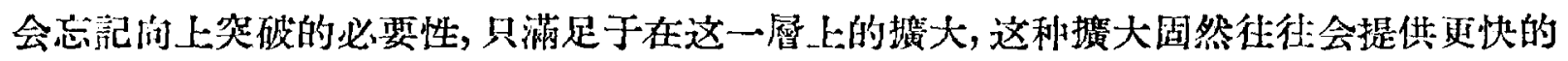
效果，但这些效果从科学上和經济上汬是比较不深入的。解决利用原子能的閒題就是組

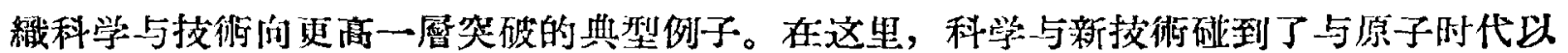

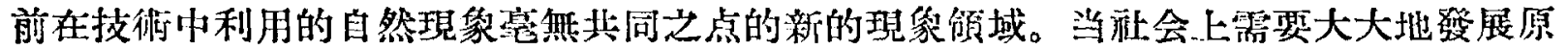

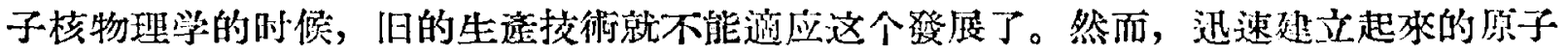

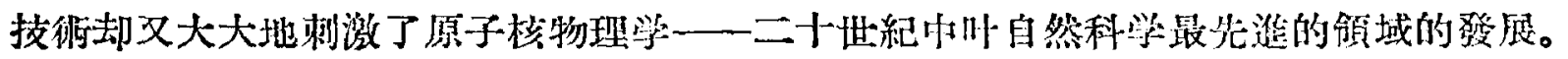

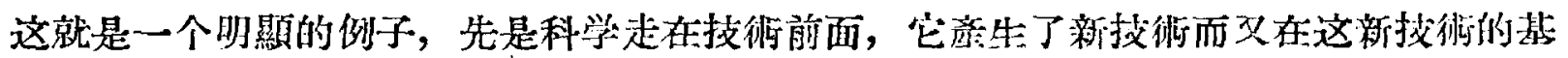
礎上得到它自己迅速發展的条件。

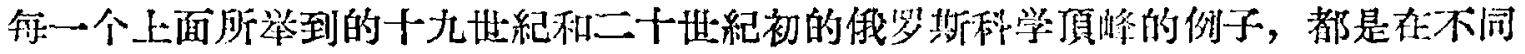

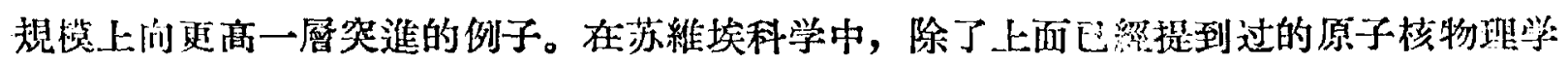

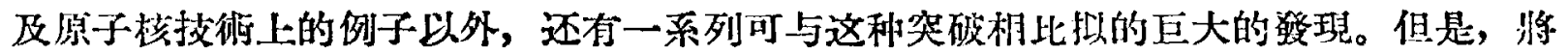
乘它們还应当更多得多。

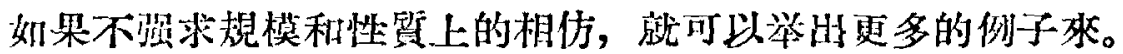

物理学方面 在苏联已細完成了关于在接近絕对零庭时物筫的狀态的基本發现

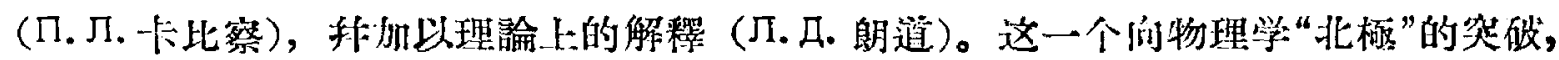
意味着对分子微覌世界規徘的新的哚入。

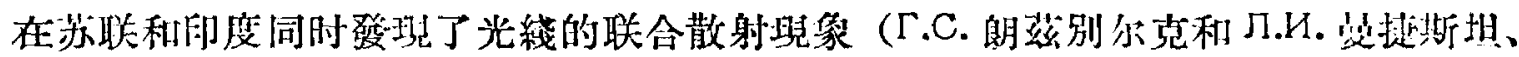
拉是）。这些發琶对研究分子結粗、分析化学和技術都有重大的作朋。

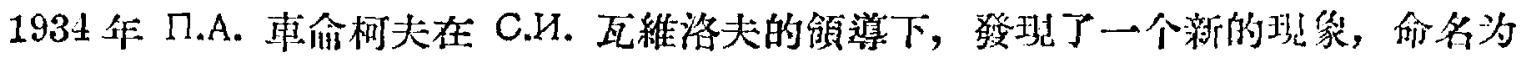

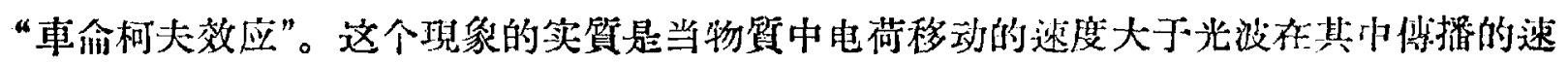
度时，电荷就放射出性翼完全特殊的光。从而給光学揭开了新的一等一一超高速光学。

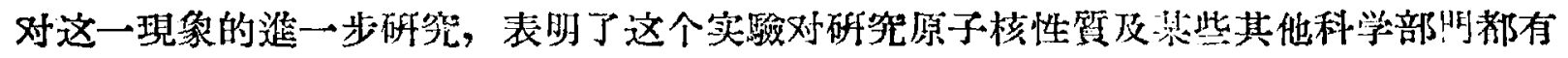
实踐上的重綮意义。

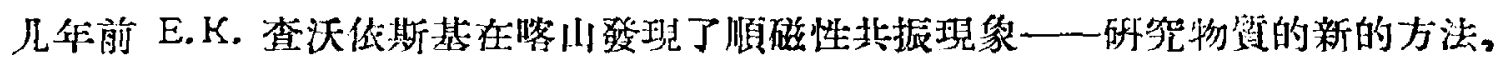

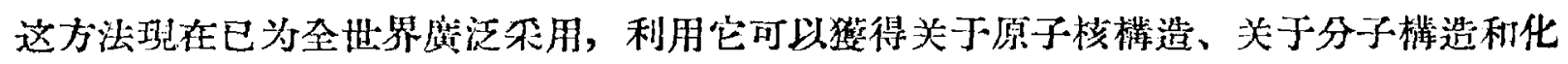

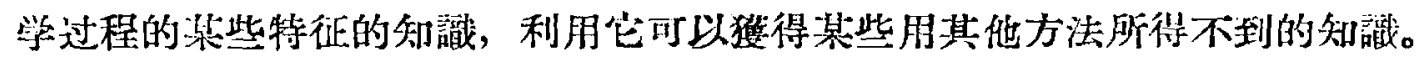

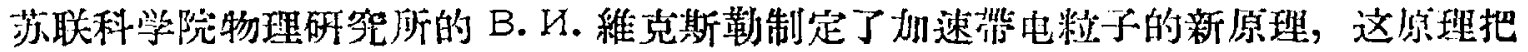
粒子可能达到的能量限度提高了一千倍以上。这原理已在苏联制造的巨大的設各中体現 了出來。在苏联, 最巨大的能量为 680 百万电于伏的同步通旋加速器已工作了五作了。 世界上最大的能量为 100 億电子伏的加速器（同步稳相加速器）即将建成。

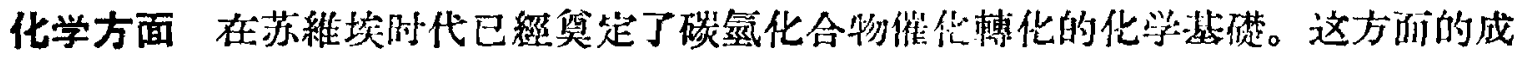

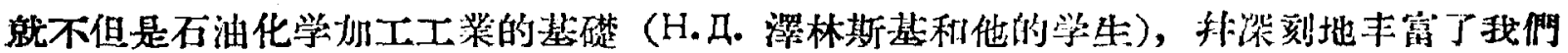
关于基本的有机化合物，卵关于碳氠化合物的概念，同的使多相催化反应理論的刢这成 为可能。 


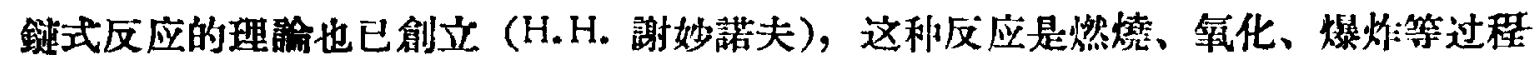
的基礎.

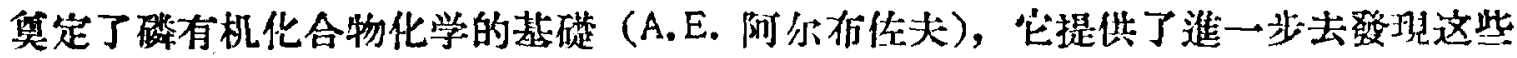
化合物的最有趣的生理性能的可能性。進一步的工作是制透嵪效能的殺虫剂和防治青光 眼的策剂等。

矽有机聚合物的發現 (K.A. 姿德利阿諾夫) 刢立了化学上和技術上的新领城, 非为

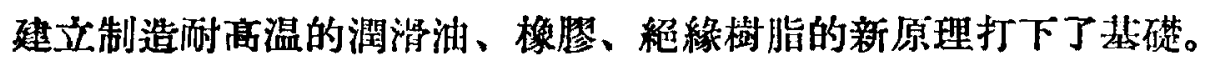

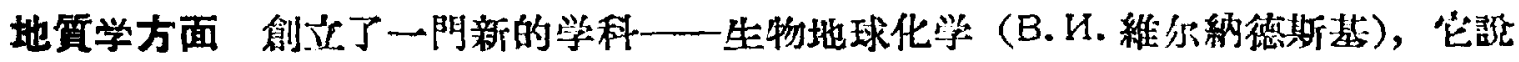
明了生物生活在地球上对地党中各元素的迁移、聚皘和敬布的作用, 投确定了相应的规

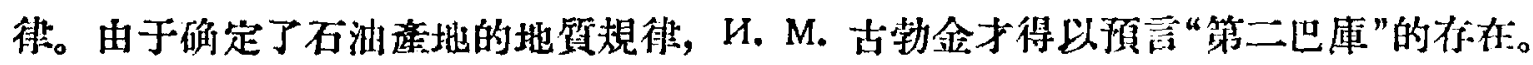

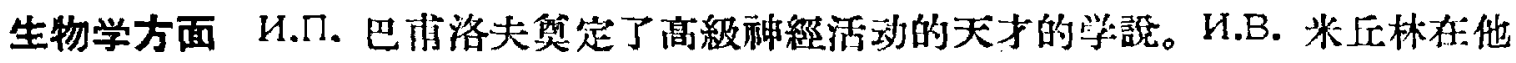
的等越的关于㓱造植物新品种的实驗基礎上，在苏維埃时代作出了对一般生物学具有重 要意义的席泛的概括。

我不再多举例子了。这些例子表明, 苏維埃科学不僅巩估了草命前俄罗折科学的成 就，而且也得到了新的巨大的成紶。但是应該指出，巨大發现的意义不是随吋都能立刻

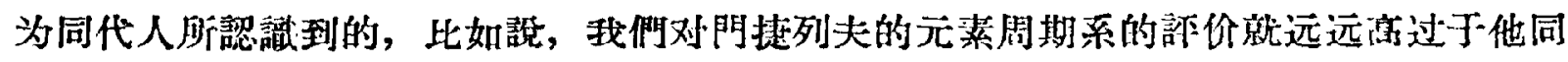
时代的最热心的人士所作的評价。

所以，要回答去年有些什么最巨大的科学發現，派常是种不怎么容易的。要程过胕

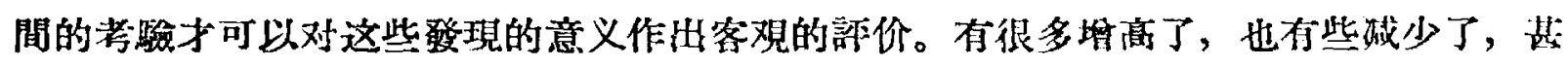

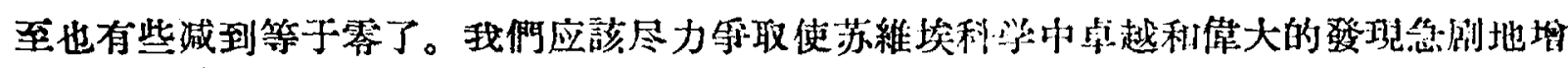

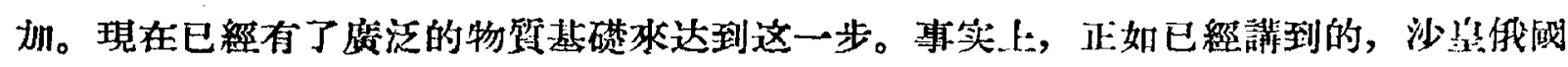
所拥有的总共不过九个大学和其他少数高等学校的实驗室。苏联有 798 个高等学校, 其

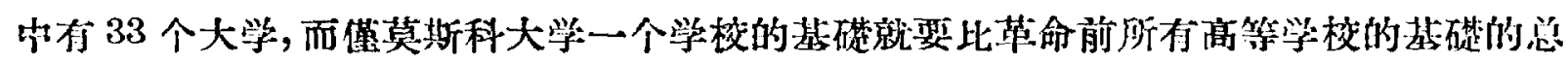

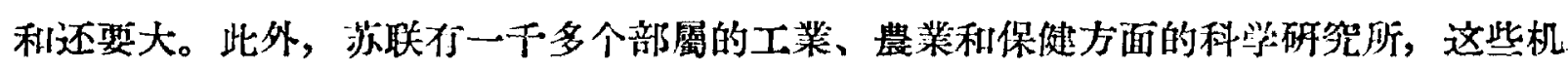
畨在革命前的俄國几乎是沟有的。最后，还有苏联科学院和它的 120 个以上几乎全部垶

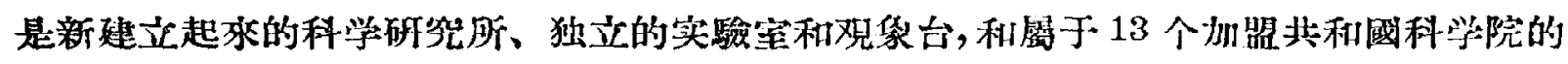
各科学研究所。对这样一个强大的科学工作者的大軍, 应該们它提出比它今天的正献大 得多的要求。

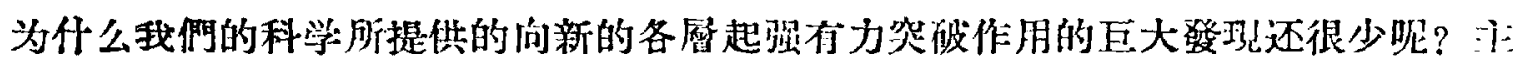

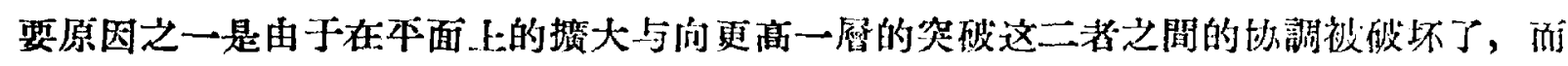

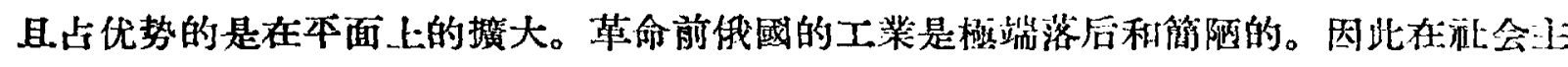

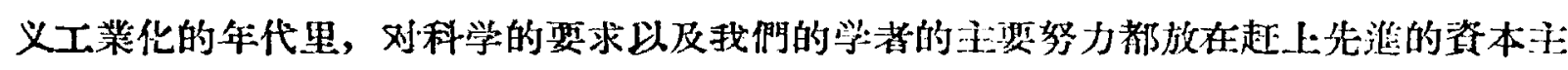

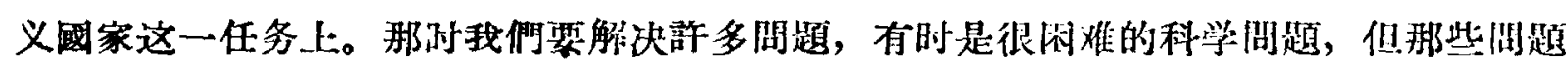
基本上是在同一臂上的据大，而且常常要去重新解决那些是已为國外科学和工丵所解决

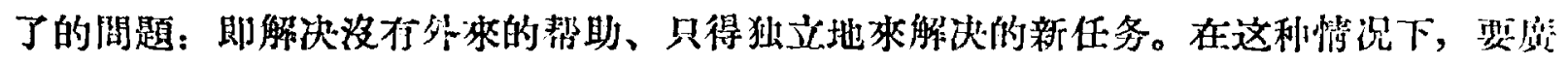

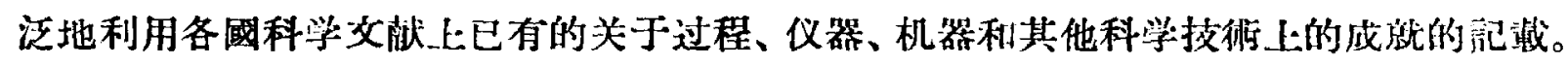
至于侴造自己的巨大的科学“僻备”, 们科学的更高一層突破, 在那种条作下就只好放在

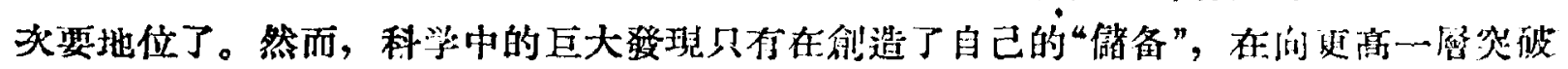


的工作过程中才可能实現。事实上，没有預先的廣泛的科学上的探查一一探索性的研究， 要想向上突破是不可設想的。

按我們的技往在走向先淮地位的狀况來講一一而且某一些技県的确已經是走上先淮 地位了一—已殌不能滿足于我國及世界科学現有的嘟备了。必須尋找新的、前所未知的 道路。

所以，在第六个五年計划中要加緊注意更上一層的各問題以及与这些間題有联系的 科学挆索工作。

不能給科学工作开一个万应藥方。达到具有巨大价值的科学成果可以有很多不同的 道路。然而在那种为了獲得技術上的結果而做的第一批尝試之前, 总是先要有科学上的

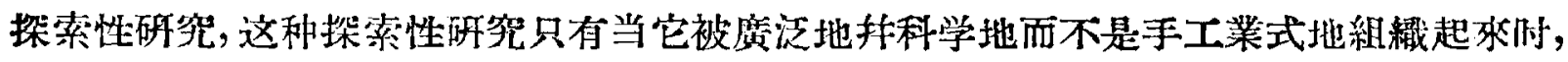
才会有成繥。在总結中一定会得到一連串的各式各样的結果, 其中一些資料支持了男一 些資料，井且整个領域被楂明了。这些結果中的一部分不能在工業中得到進一步利用， 而从另一部分中則应該挑选出为数不多的最合適的結果, 它們能决定改進技術所应臬循 的新的順利的道路，然原集中力量对它們作進一步的研究。

当从实驗室的研究饾得到了已經描述清楚的新的技術成果时，往往还要把这結果加

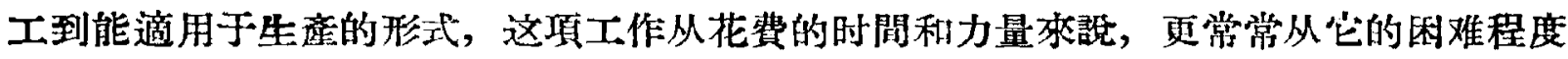
來說，也应看作主要的工作。經驗表明，这个最后任务讓工業自己去完成更为合適，为 此，就应該有各种不把全部能力本負担計划生崖的实驗工厂和車間。同时也应該提高工 厂实驗室的作用, 占它們提出任务, 使它們能皘極参加这种科学工作。当然, 原秝已在 实驗害進行研究工作的科学工作者也应該参加这种工作。

分工在这里是必需的。而且，直到現在科学工作中的分工和协作还作得很糟，这证 是我們科学所作出的頁献还太少的重要原因。

科学机关的組繊本身就决定了责任的合理分配。苏联科学院、各加盟业和國科学院、 各部的科学院（農栄的、医学的）主要应該集中力量去組㵶问科学第二尉的突破, 在这 工作中应跟世界科学协作, 利用自己援大了的科学探查一一科学儲备。

为此目的，应診运用租織手段以利用各高等学校的科学工作，应該尽力地提高这个 工作，因为其中创含着巨大的潜力。应該指出，我們相当大的一部分大学在科学方面的 薄弱是我們科学組織工作中主要缺点之一。我們來看一下，德國在十九、二十世紀所建 立的全部科学力量应归功于演等学校中的科学家們。美國即使在目前在科学淮步上起基 本作用的也是大学和其他高等学校的实驗室。拥有許多巨大的敎呼室和实羷室的大学有 很良好的可能性, 也有必要法庥泛地把青年学生吸引到科学工作中承, 他們在完成科学 探索、進行科学探查方面是很有能力的。

工業部的 (部屬的)科学砸究所应該参加淮一步探討和运用与本工業部均有关附、已 为科学所查明的資料的工作。在轉移到生的階段中，要将有关工厂的有經驗的車間和 实驗室結合起來; 苏共中央七月全会已經提出把加强工厂实驗室作为目前的重要任务。

僅僅这些还是不的的。必須要有全國性的科学計划。缺交这种計划，特別是在研究 所分屬于各有关的主管机关的条件下，将引起顯著的利行現像，这还只是一牛粗糕，更 精的是还会引起手工業方式地零碎地解决問題和搞得很分散的現像。但如果要把科学家

5 月号

科学通报 
的徒一步工作都加以“計划”那地是特別有害的，它束縛了科学的手脚，妨害了它的首倡 精神和灵活性。

那么怎么办呢? 怎样才能把各种重大工作所必需的巌格的計划与那种科学研究所必 需的巨大的首倡性与思維的自由性相結合起栍呢? 是不是可以制定獲得新的科学結果的

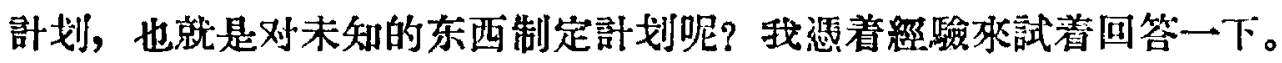

科学研究的第一个階段是探索、挆査, 这需要鹿泛的工作面和許多不同的甫们。这

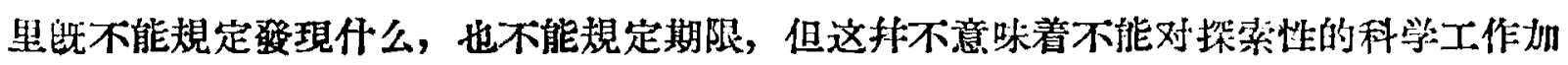
以邀当的計划。

为此就应硋分析一下科学的各个部分、可能的方向, 制定最能“丰收”的部分, 也就

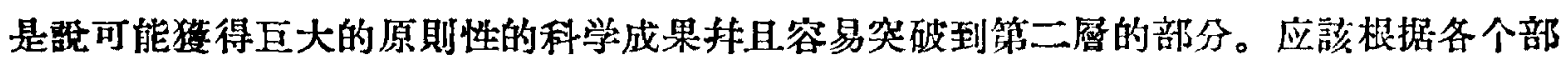

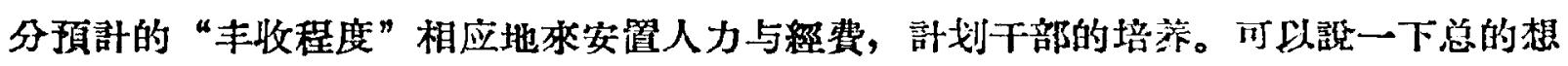
法, 以便有助于选擇那些有希望的科学部分。可以把科学的生長比拟为植物的生長。在 每个时代科学都有自己的占优势的生長点。一方面，它們是由“泟会定货”一一技術、国 民緅济等發展的需要所决定的, 这是很明白的道理, 不須再作諭証, 另一方面, 它們地 是由科学發展的队部可能性䧒决定的。后者文决定于許多因素中的二个注要因素，那就 是一一全新的現像的研究領域能够迅速增長（如：原子核物理学、低温物理学、病婊学 等); 獲得了新的有力的研究方方法的那些科学部分也能够很迅速地管辰。往往是科学的边 緣部門發展得最迅速, 如地球化学、化学物理学、生物化学、生物物理学等。这里, 把 一門科学引用到另一科学中去的研究方法得到了度泛的使用。在科学相互缷透的部分和 它椚的研究方法交文丰富起秝的部分, 可以期待最快的生長和最大的科学新發現。生 物学研究中引用了物理学的、化学的示踪原子方法而达到的警人的成就, 就是一个例 子。

另一个例子一—甫洛夫关于高級神經活动的生理学說指出了生理学与心理学、教

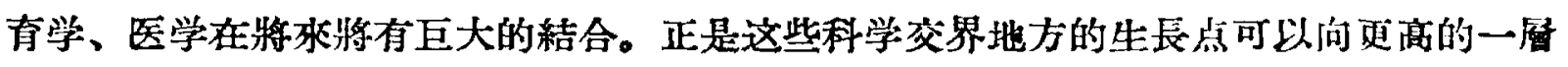
突破。相反地, 如只是在已經确定的科学部分应用一些老的方法, 那么最好也只不过在 这一啳上作些有经的必要的撗宎, 收集些非原則性的新因菜。而在坏的悄况下这甚至只 成为原地踏步。

这样, 䟣能够确定在哪些方向上要集中較大的科学挆索的力量。这他应該是科学探

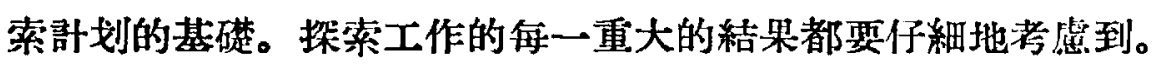

当科学中出現了重要的有希望展开庋泛的突破的項域时, 就应該对这哭破工作進行

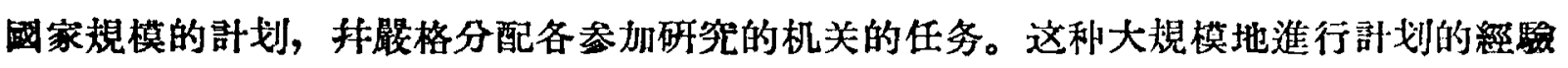
是有的, 那就是关于原子能的科学技術工作。似乎应該建立几个(为数不多的) 國家的“計 划草案”一我們把它叫做对已經探查过的部分作科学技術研究工作的具体計划。这些計 划草参將規定如何把巨大的科学問題在技術上、經济上都做到完善的地步，非且要在國 民經济中迅速地有計划地实現。只有在这种情况下，才能解除对于科学家是苦㥢的、对

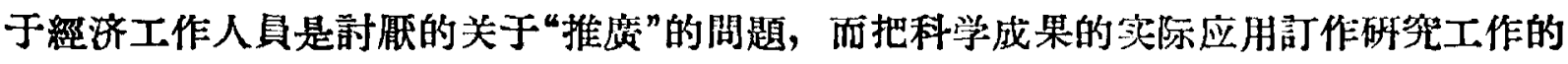
一个不可分割的組成部分, 不再延撊到許多年以后。毫篮疑間, 每个科学研究的草菜对 于科学儲备和科学探查將有巨大的、往往是主導的意义, 科生新的派生的計划草案。 
总点, 在科学探索工作中一一計划的統計原則与科学研究的首倡精神完全地順利地 䊀合起来了。在大規模的科学技術新事物成熟的階段可以有嚴格的國家計划方案。当然 除此以外，还有列于普通的各主管部門的計划之內的和由各有关部阴协作的研究工作、 合理化工作和設計工作的很大的一个領域。

我只涉及到了科学家的工作和科学与生相互作用方面的一些情况。沗外还你很多

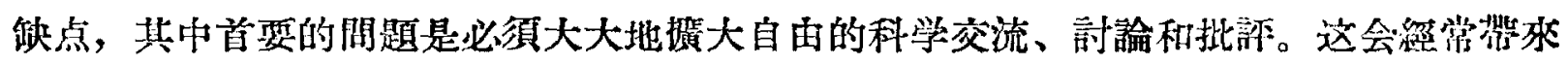
一股新䋛气流, 侹科学中确实存在的沉悶解落的空气流通起隶。正是这些方而的弱点使

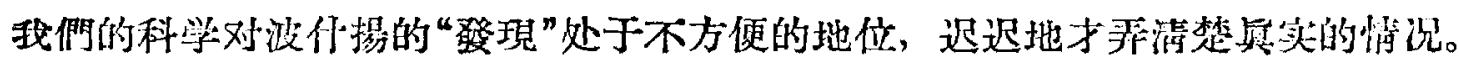

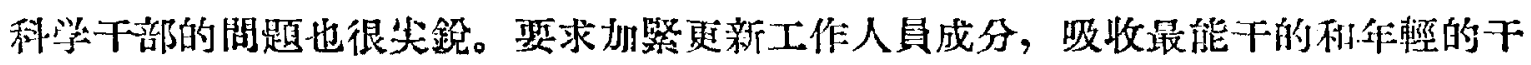
部, 更撸不称取的人員。解决此問題的方法之一是把科学研究所的活动与大学緊㴽联系 起來。

我不再沙及其他科学發展所需要的組織方面及物筫方面的条件了, 这些条作她是头 等重要的。

苏維埃科学是红怎样的成就桟迎接觉的第二十次代表大会呢, 它排分担什么要求和 計划呢?

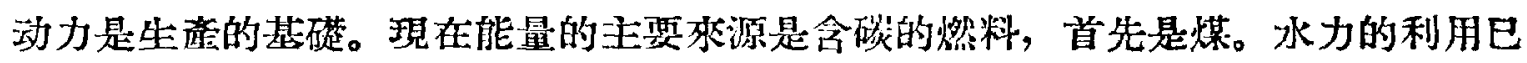
起着越來越大的作用。不論这些能量來源在我們國內是多么富偾, 但它們决不是無限止 的。随着苏联欧洲部分的河流首先是伏尔加河与卡玚河的能量的全部利用, 西伯利亞諸 河流的利用, 如安加拉河、鄂里河、叶尼塞河上的水电站建設也已开始, 这样, 水力程 鿻基本上被开發利用了。

由苏联科学院煤炭研究室与苏联地罂和碾藏保护部、苏联朵煤工業部根据最格的綜 合工作而共同制定的苏联境內煤炭眝藏分布圖提供了关于我們丰富的煤藏的㭛念，抹指 出了進一步沏查煤藏分布的方向。毫無疑問, 由于我們地睤学家的系統勘查的結果, 除 巨大的煤区資源和巴什基里亞和塔塔尔的已發現了的石油眝藏外，一定还会發現更多新 的石治行藏, 光其在西伯利亞, 那里很多地方已找到了石油礦的迹像。但是, 在我們的 时代, 自然界中种不正在形成煤和石油, 而地球上已發現的儲量与需要的規模相比也不 能境是多得沒有止境。很难講这些儲藏的用多少世紀。有些國家, 如英國, 現在已經發 生动力資源缺云的問題了。

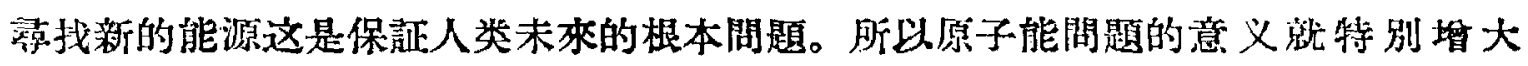
了。原子能的巨大的优越性还在于它有特別巨大的含能量的比值。一公厅鈾（主要的原 子核燃料）包含有相当于2,500 顿煤的能量。在运用“原子核燃料”的时候, 燃料的运輢

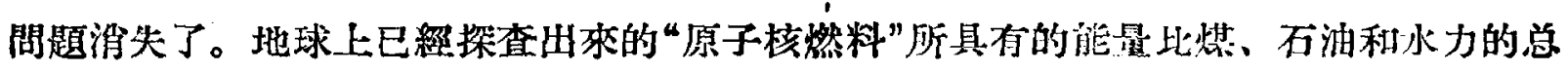
能量还要大得多。

苏联地算学家的大量工作獲得了完全的成功。在日内正举行的和本利用原子能國际

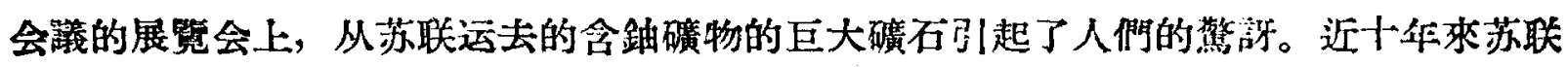
的科学家們和工程师們在提供礦物原料、扭把它制成“原子核燃料”方面完成了巨大的工 作，而且在分离重元素的同位素方面，除了在通常所用的所謂化学方法上研究了新的工
5 月号
科学连报

- 7 . 


\section{方法外，还采用了以前不知道的新型工铣。}

理諭科学家和实驗物理学家向本世紀科学的更高層实現了最大的突破。原子核的轉 变过程被引起了, 被控制了, 而且已被运用了。在苏联科学院原子能發旺站冲 $\mathrm{H}$ 日夜夜 地精确地調節原子核反应过程, 使得被燃燒的鈾棒放出自己的能量, 这能量被蒸汽溚輸 和發电机轉化为电能。科学家与工程师們从理諭上和实踐上掌握了这个各方面都比㗼逝

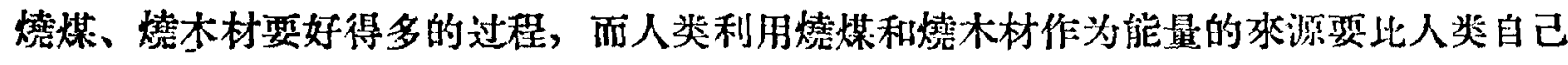
的記筫还要久，这的确很有意思。今天的实驗工作的重要結果就是要在第六个五年計划 中建立更大的原子能發电站，其总功率为200-250万千瓦，而且登电成本在初期就将与 火力發电的成本不相上下。因为随着这方面科学技県的進步，成本降低的可能性非常之 大，所以得到这样的結果是極其有希望的。

展望將來，我們看到了困难而有巨大意义的任务一一利用热核子反应本取得能贵，

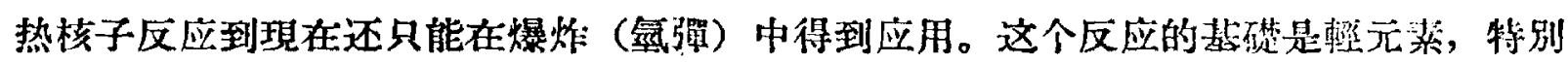

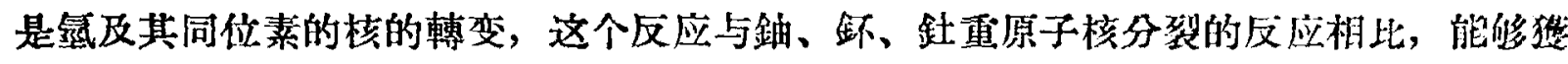
得更大的能量。太陽的能量就是西热校子反应而迹生的，所以利用这和反应会仿人們能 够得到字宙規模的能量。

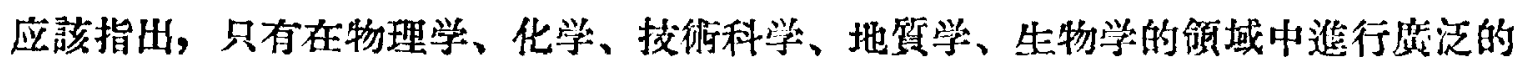
非常度閣的研究的基礎上，才能实現原子核物理学和动力方面的问这高一層的巨大突破。 非常重要的最优秀的一部分人力和大量的資金花費在这个工作上了。如果不这棬，这个

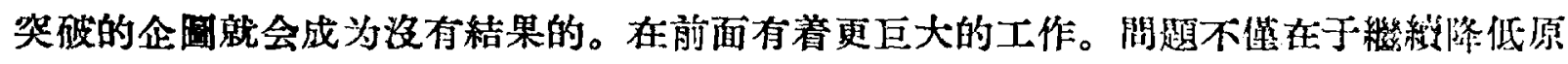
子核燃料电能的价格。間題还在子在各利运输工具上应用这利能量。随着原子核反应将 生成放射性元素的复雜湿合物，还需要找出这些元素的用途。利用原子核轉变过程中得 到的基本粒子一一中子能够制造各种元素的放射性同位素。不諭用什么方法制成的放射 性同位素, 其化学性筫与晋通元素一样, 可以用來作为示踪原子, 这是科学䃑究上的一

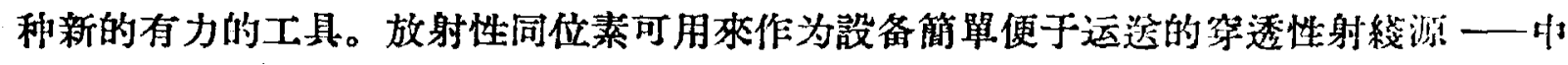
子流和各种“硬度”的 $\alpha 、 \beta 、 \gamma$ 射棧的射源，它有着与 X 射馢相同的性筫，可以在医䒬上

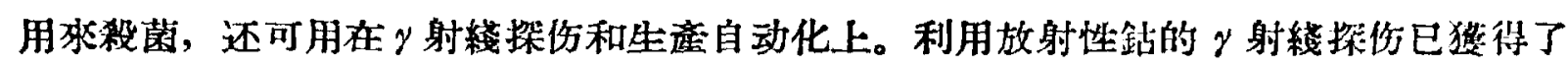

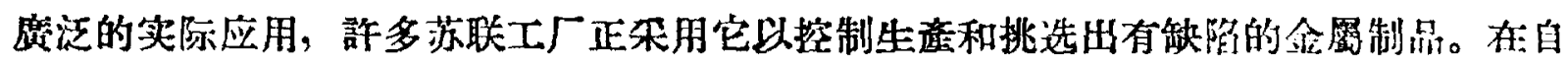

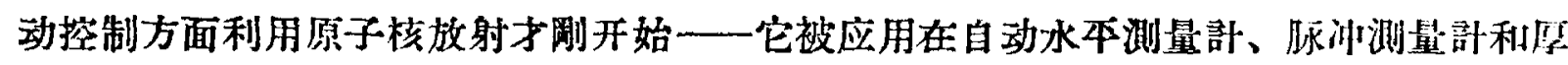
度測最計中，以調節生逢过程中的有关参数。研究这些射馢对遗傅現像的影响是很重要

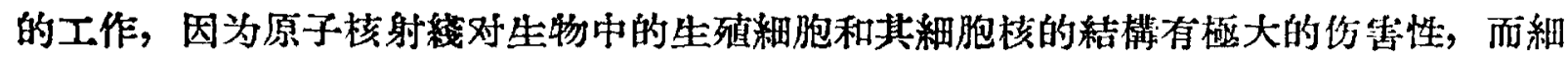

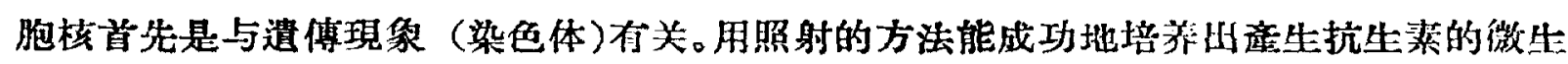

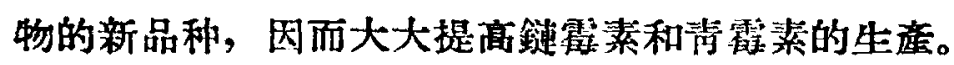

示踪原子是現代科学的恩惠，特別是对生物学的研究，这是因为利用它就能的容易 追查原子、分子，或分子的一部分所走的道路，而看到它們在有机体中的轉变。許多不

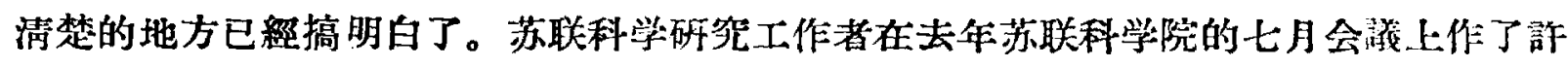
多报拈，后來于 1955 年 8 月在國际和本利用原子能日內瓦会議上地作了一系列的报少。 在这次会撞上苏联科学家們的工作得到了很高的評价。在动物和柆物有机体中新陈代謝 的許多問題, 因为利用了示踪原子, 已被搞清楚了。例如大家都知道, 磷的代蹲对有机 
体有着巨大作用。动物脑的兴奋和挪制（休眠）过程的研究，揭露诂在这阿种状态下磷 的代謝强度差异極为㙷著, 这样就發現了巴甫洛夫所建立的腦的各个部分兴南和抑制过. 程的生物化学方面的基礎。

烏茲別克的学者利用磷的示踪原子証明了在棉花成熟之前, 在所埍根外迎肥时, 磷 肥可被棉花的叶子吸收。在烏茲別克的一百万公頃的面積上，梁用了棉花的根外追肥。 同样在甜荣上如覌察到了磷的根外吸收現象。与一般的对植物生理直相的看法好像相 反，苏联生物学家証明了植物不僅由叶子从空气中吸收二氧化碳气，同时也从土缺中释 过根部吸收，当然吸收的程度要小得多。如上所迅，A. E. 阿尔布传夫在喀以的研究， 笑定了磷有机化合物化学的基礎。这类物質中的某些部分顯示出具有警人的殺虫能力, 它們極其可能会排挤掉其他殺虫(農作物害虫)效力較低的菜剂。一系列的苏联科学机棈 正从事着这方面的探索研究。莫斯科的科学院与列寧格勤学者們的合作, 獾得了最新的成 就一一發現了新型的“內吸殺虫剂”。这种程虫剂之所以称作“內吸殺虫剂”是因为在噴酒

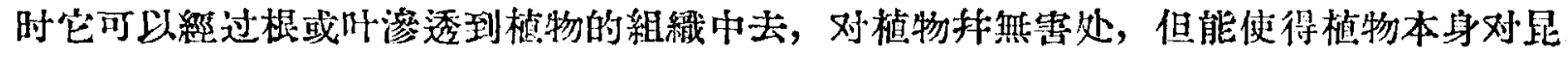
虫具有表性。这里新奇的是在播种前用这种新找到的物罂的稀溶液处理种子所黄生的內

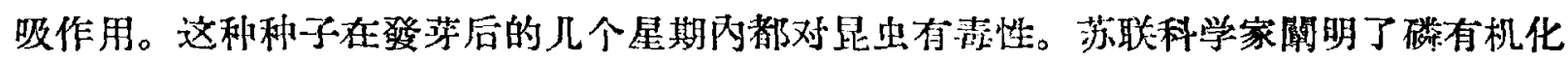

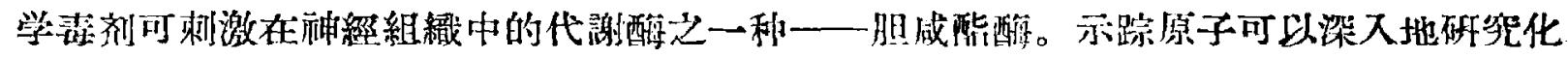
学素剂的援散道路及其作用原理以便使它能起更大的效用。

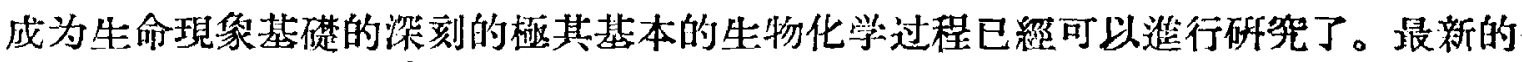
电子䋶微鏡能区別相距 $15 \AA$ (有机化合物中碳原子的距离是 1.4-1.5 $\mathrm{\AA}$ ) 的点, 与使用 这种㙷微鏡的研究方法相結合, 生物学家獲得了们生物学更高一層突破的强大武器, 不

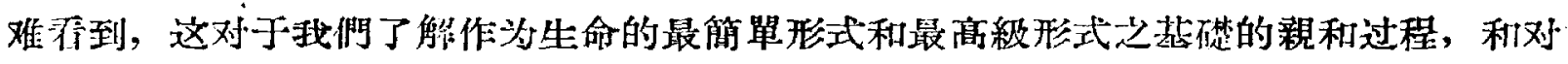
于把生物学利用于实际一一用到医学和農業上, 具有巨大的实际意义。在苏联必须立刻 迅速地提高和席核墢展实驗生物科学。

们科学更颜尿的巨大突破一一掌提了原子能和發展了原子技術一一促進了新突破的 可能性。

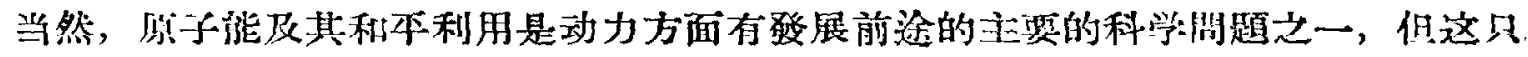
是說三要的，而不是唯一的。固体物理学和晶体物理学方面的研究，㖞簬了巨大的技獄 上的可能性，此可能性是叮于晶体中原子結構的噘格規律性和对这种結棬规沚㭠的微小

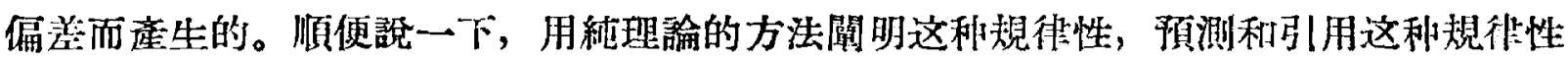
到所有可能的晶体結構中去的工作是俄罗斯科学的功精 (E. C. 費德洛夫的天才工作，以 后劳埃在鍺中發現的 X 射綫对晶体的衍射, 和如今起着巨大作用的 X 射綫結粠分析法,

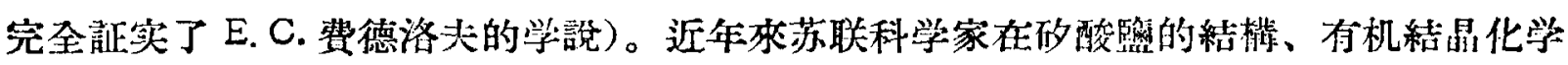
和絡合物化学方面的研究，对这个方法的發展做出了巨大的汿献。

苏联科学院的各个物琴学和結晶学研究所的許多工作是有关于利用絬品点陳的规徘 性的工作，在这些工作中合成了超硬度的晶体一一剛玉和紅宝石，制造了用在各种光雖

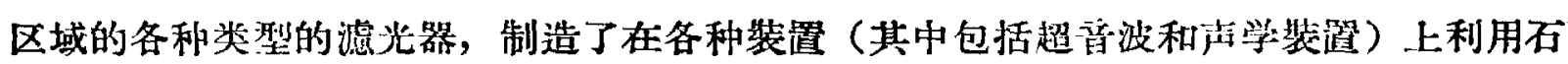
英作为压电晶体的方法，發現了新的优質的压电晶体一一鈌酸鎮。

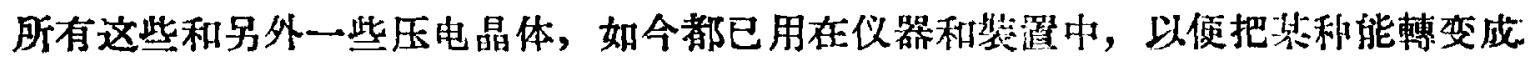

5 月号

科学通报 
另一种能，例如借助压电品体可把机械能轉变为电能，也可以作相反的轉变。最近牛薄 体特別吸引了科学和工業的注意, 牛導体是这样的晶体, 它不像金屬那样具有多量的自 由电子，也不像电介質（紹緗体）那样把电子都牢牢地固定起來。

苏联科学家 (A.Ф. 約飛及其学派) 在坐導体的理䜽方面作了極其重大的貢献。外國 科学家研究出了有很大实际意义的制造楆純的鍺（就是門捷列夫根据他的周㑢系所預言 过的类矽) 和放的單晶体的新方法。現在用这些晶体制造了整流器 (从仪器上用的小型 的到动力裴活上用的大型的都有) 和放大器一“三極管”。为了达到这些成果, 茄联科学家 最江地進行了不少的工作。在 1955 年, 苏联科学院物理技術研究所制造成了第一个巨 大的动力整流器。牛溥体研究所成功地在進行着直接把热能轉变为电能的工作。这里最 近的成就, 是成功地用牛導体热电元件把热能轉变成电能, 其效率达到 $10 \%$ 。理諭指出 了应該如何再向前迈進。在國外最近也正在开展着同样方向的研究; 那黑所达到的效率 相当低, 但是他們將很快地穼取措施以登展牛導体的焺究工作。热能轉变为电能的效率 其理論上的極限值与热力学的極限值一样, 都决定于卡諾循坏。但是这方面已䌈达到的

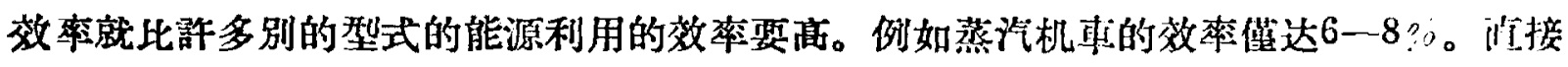
把光能轉变成电能預示出扭在一定程度上肯定了南方沙漠地带中利用热和光的誘人的远

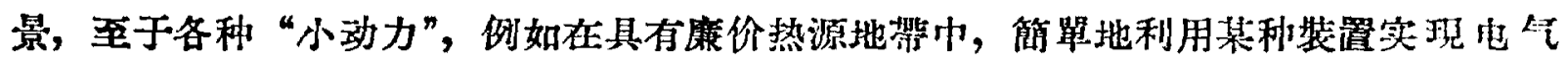
化, 它的远景更不用鿁了。

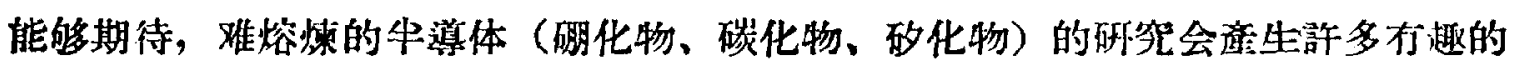

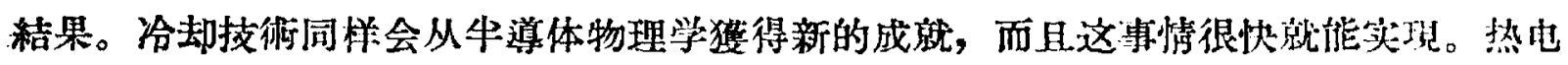
元件通过电流时有一个接合处会被冷却，如果把它們串連起來，則可降低温度 $60^{\circ}$ 或更

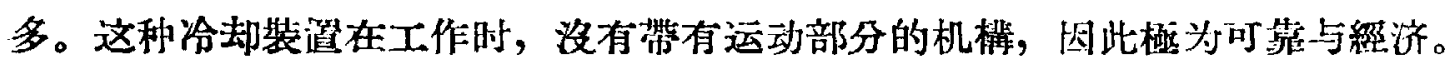

作为例子的这雨个工作环節——原子核物理学和坐導体一一詵明了技術進步的新的 可能性，这种可能性之所以能够实現，是因为首先有了哚入的理論，在前一个例子里是 原子核的理論，在后一个例子里則是晶体的原子結棈的理諭。这些都是以各种規模问科 学更高一層突破的侧子。

不論原子能或是牛導体在动力上的利用，对末來的技修都有着無限遥闊的远景。科 学应該注意动力中的那些不論是对現在还是对将來的枝術都是刻不容䋁的闵題。

热电站的新技術方面的工作有着巨大的意义，因为在我國一直到不太远的将秘，大

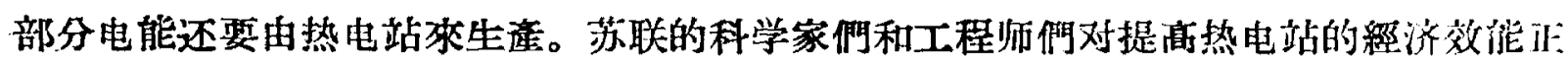
順利地淮行着工作。首先要大大地提高蒸汽的参数: 压力提商到200-300大年压, 湿度 提高到 $600-700^{\circ}$ (現在度泛朵用的是 90 个大气压, 温度 $500^{\circ}$ )。制造这利施的多全全地

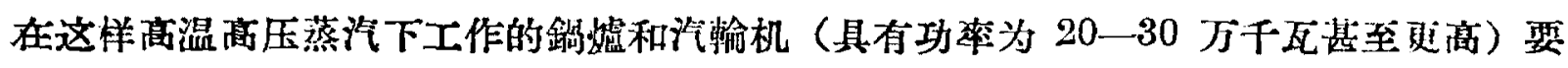
求用最新的研究方法（其中最优越的是放射性同位素的方法）去哚入地研究各个机組的 工作过程。识温高压下金屬的研究也有不小的意义。

苏联科学院动力研究所所制訂的在热电站中动力一工嶨綜合利用燃料的方法, 开辟 了新的远景。电站将不僅成为电能和热能 (其形式是蒸汽和热水) 的來源, 而同样也

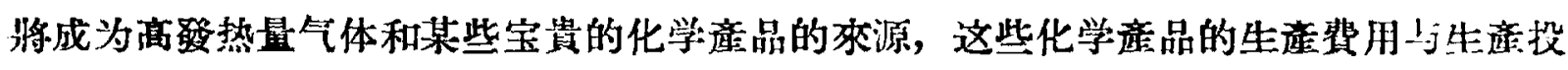
資, 要比在翠独生遮的情况下小得多。这方面的第一个工業設备已在進行工作，其他的 
装置正在建設和設計中。

在远距离輸电方面也有着一定的科学技術成就。战前設計的古比雪夫一一莫斯科之 間的輸电方案要用六个回路, 毎个回路輸电量为 15 万千瓦。現在輸电功率已超过一百 万千瓦，但由于乐用了提高輸电能力的新方法只要雨个回路就的了。現在該要設計距 达2,000公里, 功率数百万千瓦的輸电綫路了。为了更經济, 应硋朵用比 400 个伏更阔的

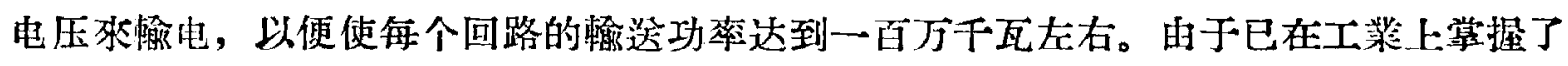
直流商压的技術，因而开辟了新的超远距离輸电的远景。以我國年端电能 7,500 镱下瓦 小时的水本而制訂的統一輸电系統的初步方絮也已拟定了。

苏联統一动力系統的科学技術基本原則正内苏联科学院 $\Gamma$. M. 克尔日然諾夫斯基动力 研究所、各加盟共和國科学院的許多动力机權和部屬的專門的研究所和設計研究所制言 中。統一动力系統能保証各种动力資源和动力設备 (也包括原子能發电站)得到最有效的 配合, 还能使國民絰济的动力基礎达到最大限度的机动性和節約目的。統一动力系統的

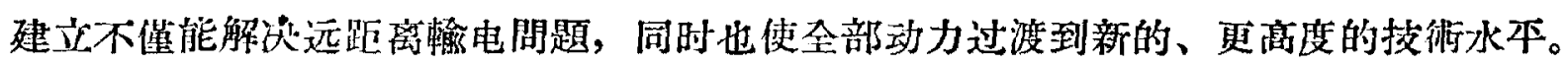

快速电子計算机的制造在某种程度上講, 是同原子能方面的突破一样有前途的问科 学和技術更高層突破的例子。新的技術，特別是原子能技術，提低了如此大量的計算要 求，以致于舆論那个計算机关，如果用老的机械的計算方法（例如手算和电动計算器）

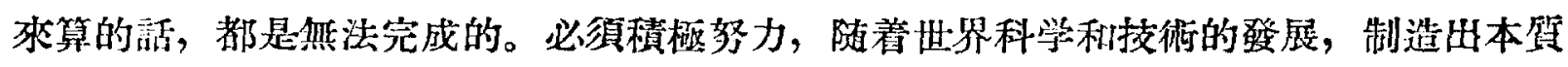
完全不同的新型計算机。过去管制造了其中的儿种。下面我談談科学院制造出來的，非 且已緸用了兩作光景的快速电子計算机。这个机器是以几个新颖的原理为基礎的, 它是 欧洲运算速度最快的一台机器（它一秒鎆內能完成 7,000-8,000 次三个位湿的运等，能 代替几万个計算者的劳动)。

由于运算速度很快，这个机器与同类的机器都能够解决以前不能用計算方法解决的 数学阔題。从而为很多科学与技術部門提供了完成質的躍進的前提，这些部阿本來的困 难就在于大量而又要迅速的計算。然然今天的快速电子計算机还不是最好的，在程哭起 來的經驗的㸃礎上, 可以預期很快地制造出更新的、更輕便的和运算速度大得多的机器。 快速电子計算机具有储存原始数结、中問計算結果和計算程序的“記喓力”。这种机器还 提供出印好的結果，例如，印成表格的样式，可以直接逘去印刷。机器的每个元件都随 着新的科学研究的發展不洌地改䈍着。

数学家局負着巨大的工作。任何一种問題都要加以呼究, 以便遊应計等机的要求。 这项根据問題編制許算程序的工作，需要一种全新的处理数学各部門的办法。我們们数

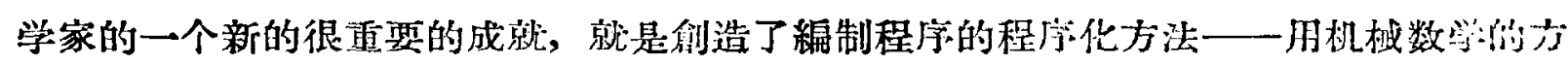
法來編計算程序。

計算机还只是剛㴊开始自己勝利的生㴼。可以預料将会有許多能勝任罚些方面工作

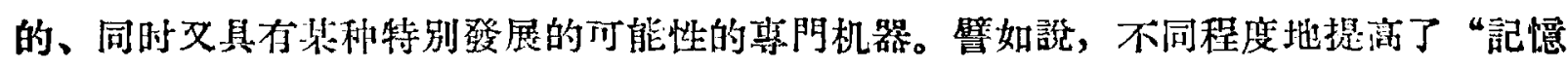

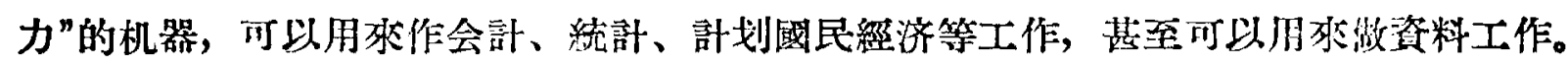

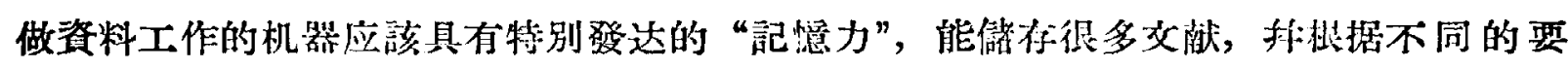

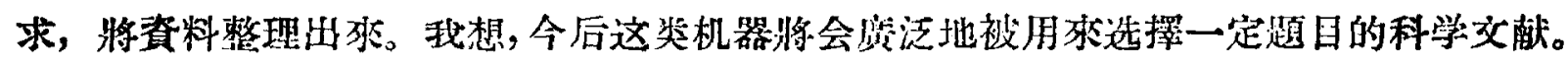
这种工作現在还花悲科学研究人具很大一部分的时間。適用于一定的遙輯运算和一定的 


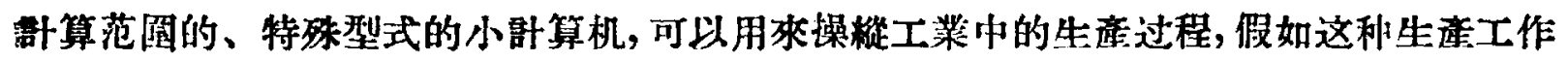
的進程是随着相互独立的可变参数而变的話。这种生严过程如果用最普通的自动控制, 則必需要工程师参与工作。而用計算机控制时, 自动机就可以代替工程顺。

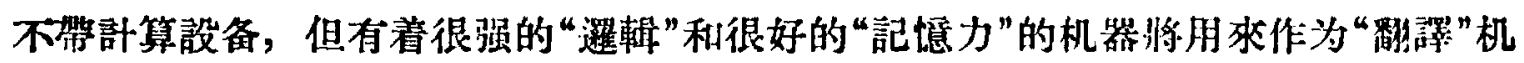
器, 甚至 (虽然这初听起來似乎是幻想) 也能作为“文学編辑”机器。至于珫用机器把一。 种語言譯成另一种語言, 这已成为事实了。就是那一台快速电子部算机, 虽然它不是尃

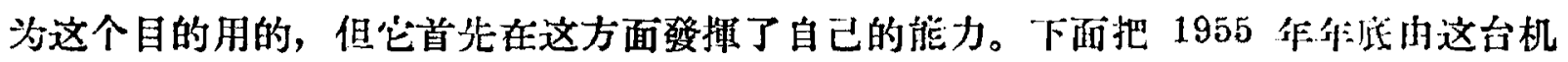
器初决从英交試譯成俄文的一段文字中的一句話做例子:

In problems of this type numerical

В задачах этого типа числөнные methods become a necassity due to absence of other methods for getting the requisite information out of the differential equations.

методы становятся необходимостью, обусловленной отсутствием других методов для получения необходимых свелений из дифференциальных уровнө:ий.

应該指出, 筸有三个曹門翻譯人員与这个机器同时淮行翻譯以便比校, 結果这个机

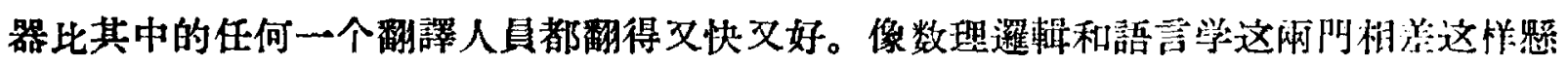

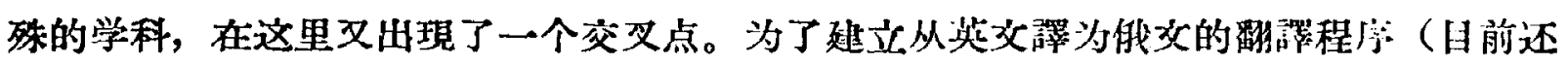
是試駼性的), 数学家和語言学家业同進行了許多工作, 这个工作成果的意义, 除不僅限 于机器技術方面, 将來可能会具有更厥泛的意义。

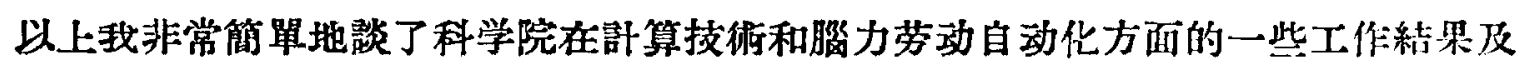
其远景。我还不能涉及那些剛开始实际应用的成就, 例如, 同样用途的計算机们新的權

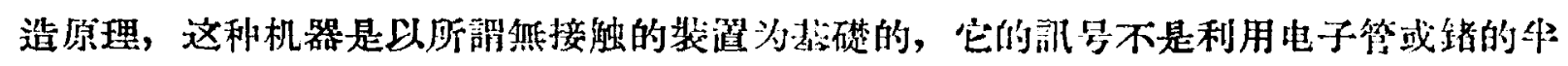
尊体放大器, 而是利用电磁城应。

我只能㮶略地提一下科学院的某些对國民維济有㨁接帮助的工作。

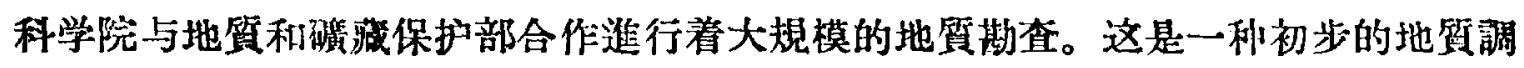

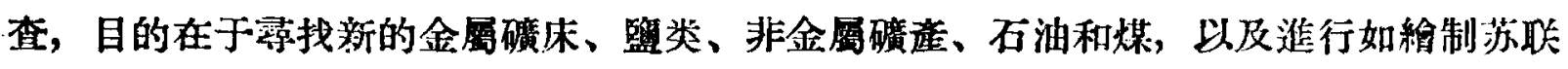

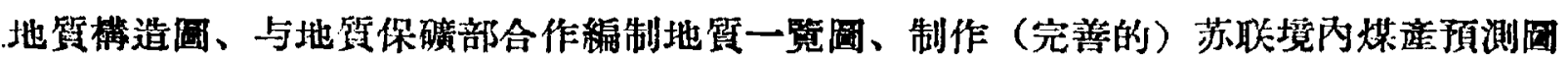
等管的称合工作。正在研究桸有元素与分散元素的新來源, 关于这些元素的碳愿料基 地正做着附有推荐書的系統报告。在考察工作的基碟上, 科学院建諓政府發展已由科学 院進行調查的区域的生迹力。例如，关于建立巨大的远东冶金基地的建淁、关于以利用

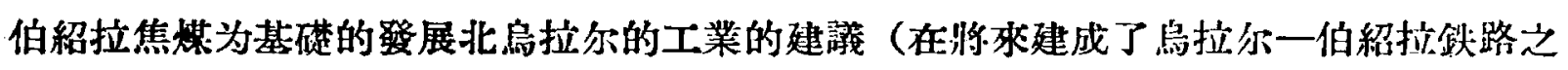
后)、和相应地發展貝加尔湖以东地区的生索力的建請等。在苏联境內大規模地非行着 土堆研究工作投編給成圖, 科学院所得到的这些資料不㮖运用在目前的工作中, 也运用 在新的巨大措施，如灌激工程和选摆荒地方面。

科学院在从北極起的苏联領土上以及在远远越出我國國界的部分地区上，進行着地

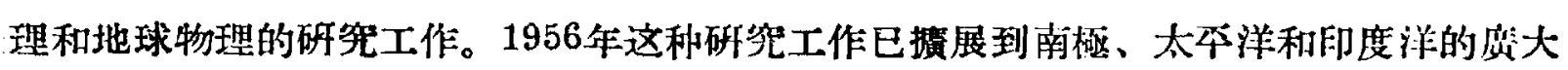
地区。

地罂学發現原生碛物原料，采磺工業开穼原生礦物原料，而治金工業和石油工業则 進行这些硔物原料的加工。冶金中的重大閒題是焦炭。科学院在这方面的工作取得了雨 
个重大的具有國民綪济澺义的成果：第一，制訂了一个新的、非常有前涂的选煤方法，

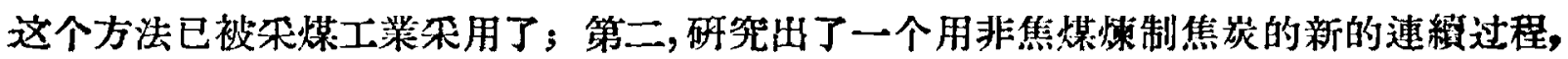

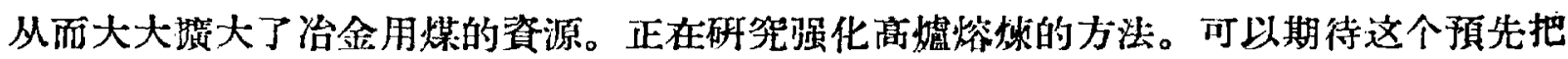
煤加工和军用橮气的方法会得到很大的成就。

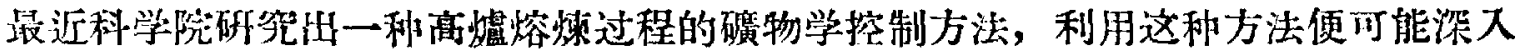

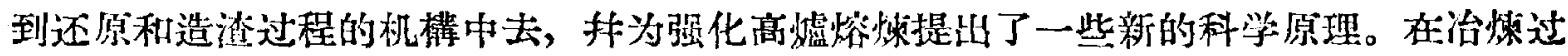
程中运用㠱空的方法是非常有前途的。例如，利用这科方法能够得到会气最少、具有較

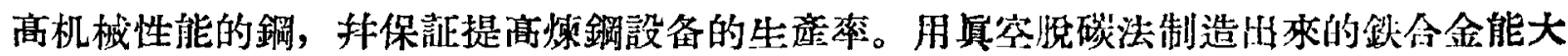
大改善合金鋼的犋量。

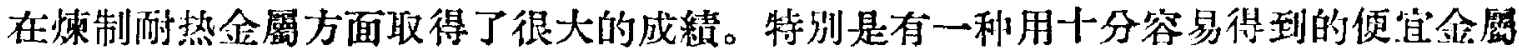

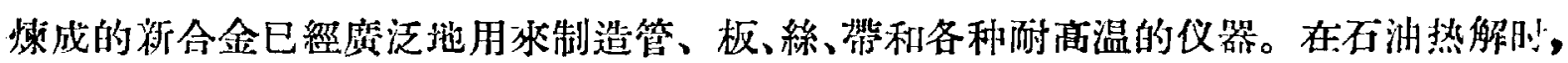
利用这利全金制品，可以大大提高設备的棌定性和增加希望得到的產品的彥昷。

在石泊加工方面，科学院研究出来的加工含硫的暦青基石油和重菂的新方法，对工

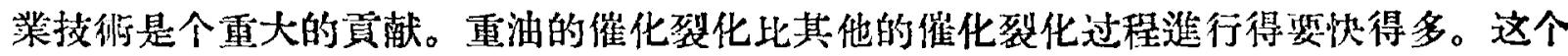

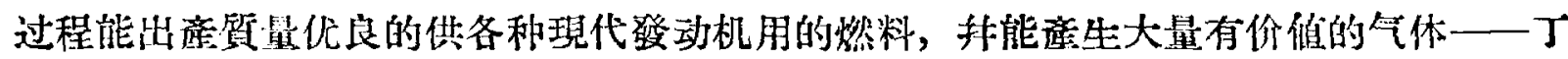
二烯、丁秌利特別多的乙烯。

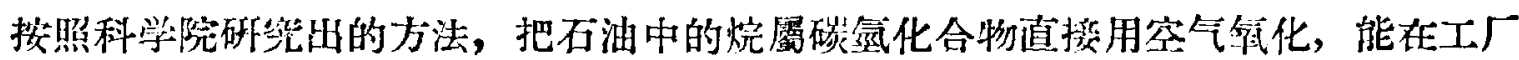
中制得大量的高級醇，用这些高級酸类可以制造去垢剂(肥㫐的高級代朋品)和消潤剂。 現在正建設許多新的工厂，在这些工厂里将军用这种方法，这样就叮以大大笁得用于生 﨎目的的宝做的食用油脂的消耗。

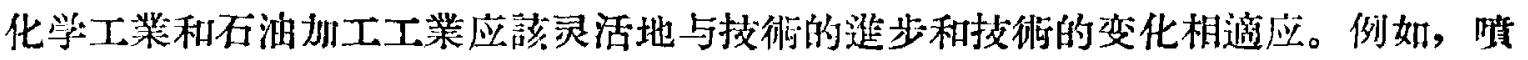

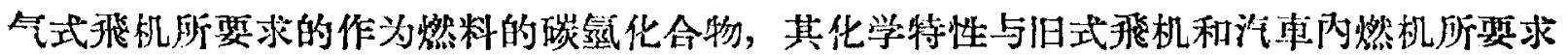
的完全不同。就是后者, 随發动机櫣造的淮步, 对燃料的要求也有变化。石汕的化学特

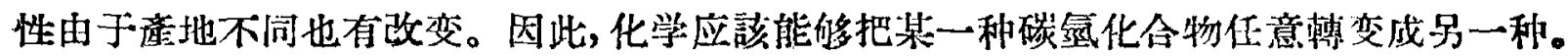
苏联化学家正在用多相催化的方法成功地完成着这些任务，多相催化現像和多相催化本

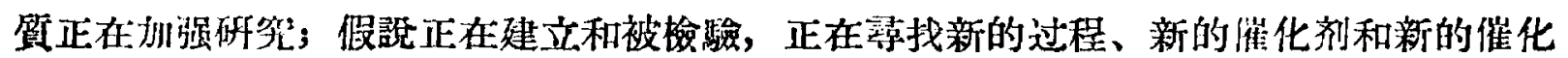
类型。

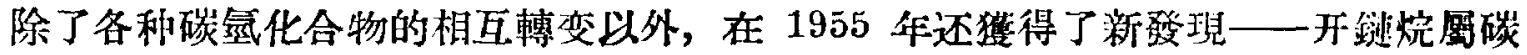

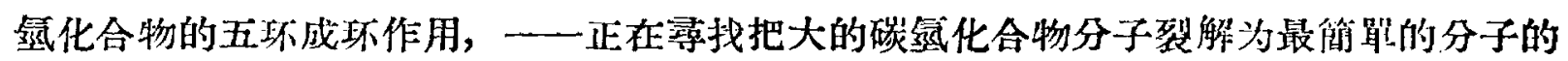
方法一一裂化。正在尋找从最簡單的分子合成复雜分子的道路。正在進行極全䧴的（防

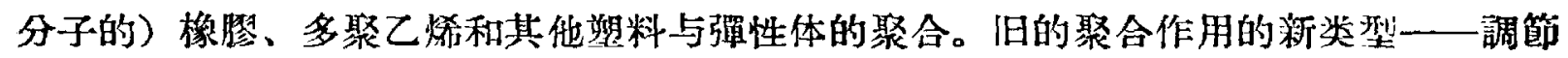

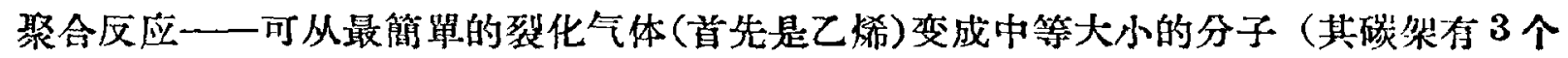
到 20 个碳原子)。这个新途徑是由科学院同化学工業部和輕工業部合作在進行蠅試驗 以后提出的, 可以肯定, 这个方法有很大的前途。科学院的实驗室对这个过程進行了全 面的研究，在乙烯和四氮化碳的調節聚合的基礎上獲得了500多种新物翼，对它們的轉

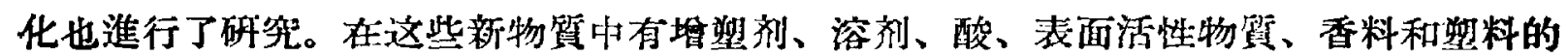

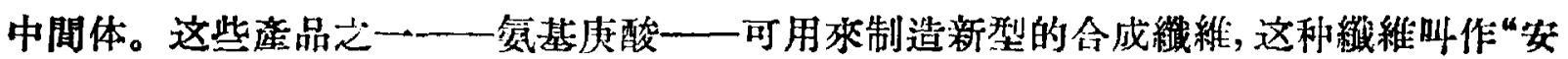

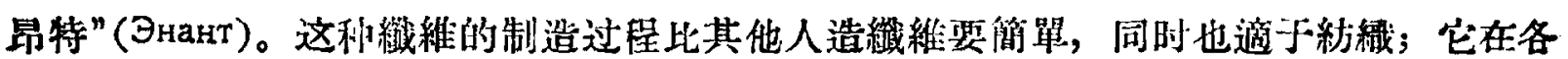


方面要比卡普綸更坚固。在化学研究的其他領城中一一無机化学、分析化学、生物化 学——也有許多科学上的和实际应用上的成就。

我只能談到同苏联科学院的研究所以及和苏联科学院的研究人員有关的一些科学成 果和科学远景, 首先是想要閣明本文前一部分所發揮的思想。

苏联共党第二十次代表大会是我國國民經济和交化高漫的强大的因素, 是我國沿

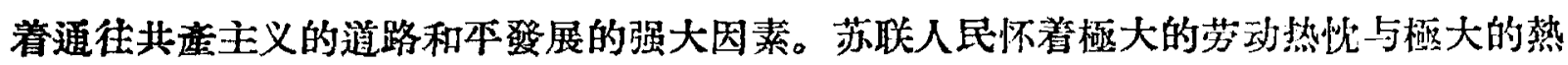
情, 热烈地迎接我們祖國生活中的这个重大事件。苏联共道党第二十次代表大会关于 1956-1960年苏联弡展國民經济第六个五年計划的指示草案问苏联的科学和工藻提仙了 关于大大發展科学和技術, 关于在工業中迅速掌提科学成果, 以及关于提高我國人民的

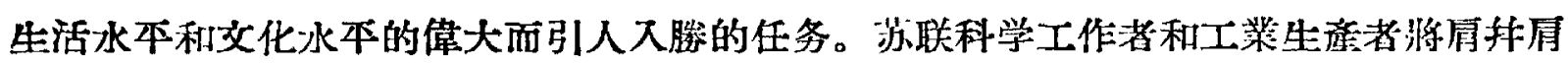
地怀着兴奋的心情來实現偉大的共善党第二十次代表大会的指示, 把它看作是自己的責 任, 看作是自己的光荣和豪迈的事業。

[累木天 周 明 李德元譯自“苏联科学院通报” 1956 年第 2 期]

\section{〔上接 28 頁〕}

輪船航行路綫上面去。利用这和自动控制的設备, 其中包括有天体测量和电子訕算机的

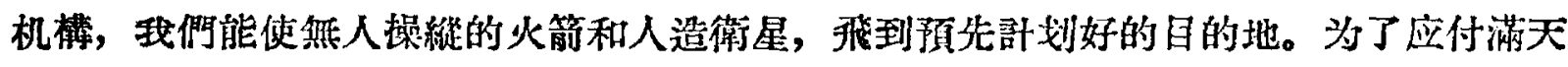
都被云遮的天气，現在正研究使用無綫电六分仪來覌測天空的射电源，以代替光学六分

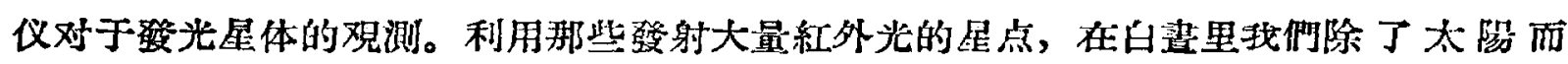
外，还可找到其他的天交定位观测的目标。

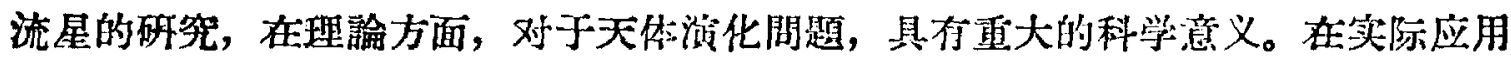

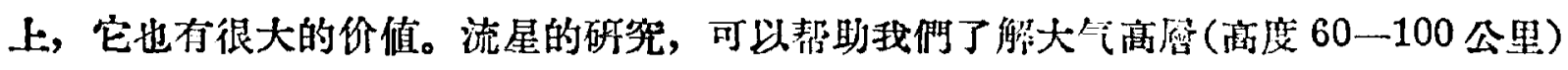

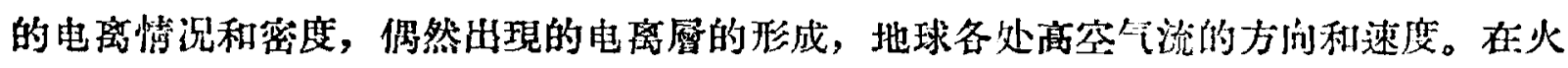

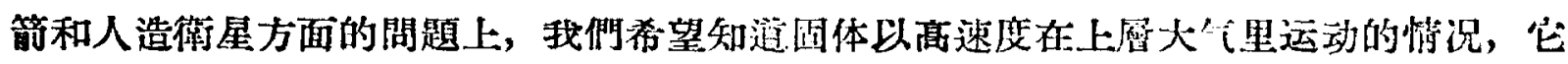

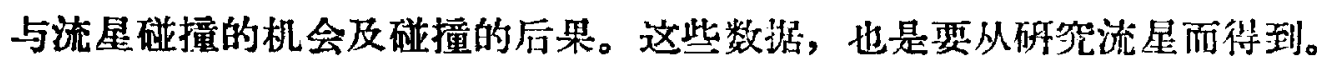

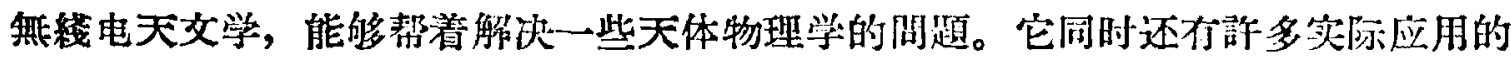

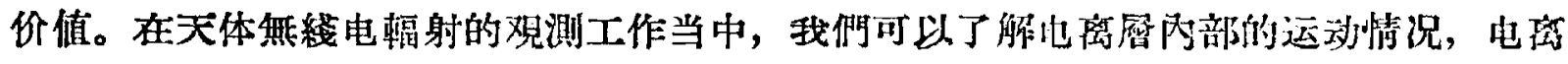

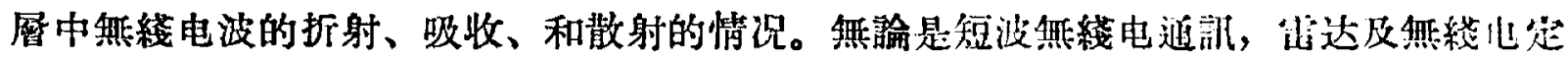

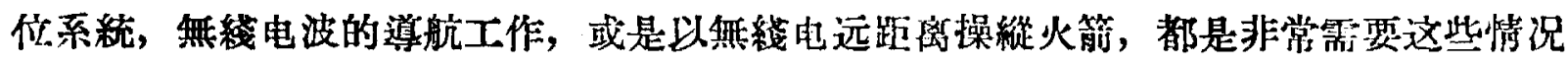
和数据的。因此通过船綫电天交学的工作，桃掌握这些情况; 具有巨大实际应用的价 值。

[李 競 沈良照譯] 